\title{
ANÁLISE DE UM CURSO ONLINE AUTOINSTRUCIONAL NA PERSPECTIVA DOS CURSISTAS
}

\author{
SÃO LUÍS/MA JULHO/2018
}

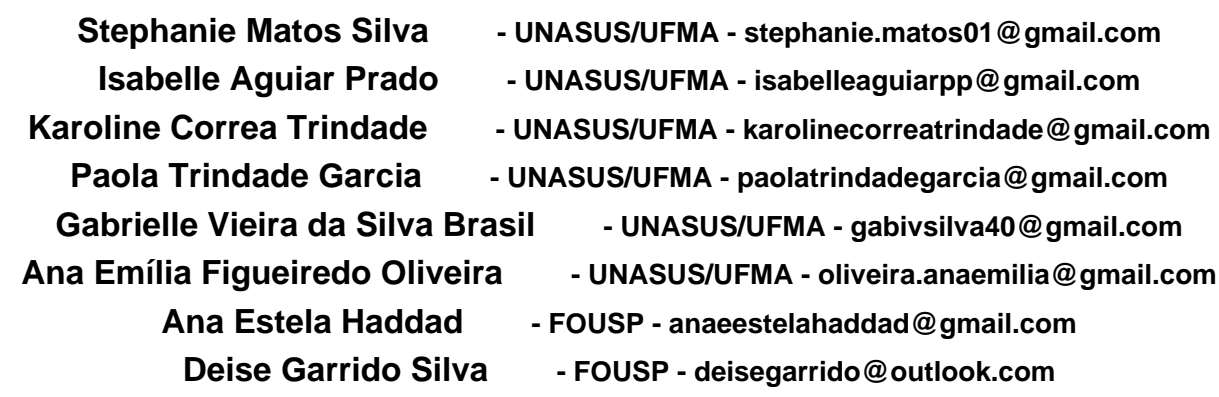

Tipo: Investigação Científica (IC)

Natureza: Relatório Final de Pesquisa

Categoria: Pesquisa e Avaliação

Setor Educacional: EDUCAÇÃO CONTINUADA EM GERAL

\begin{abstract}
RESUMO
A avaliação é parte fundamental no processo de desenvolvimento de projetos em educação a distância $(E a D)$ na medida em que permite que devolutivas sejam fornecidas de todos os atores envolvidos, principalmente os discentes. Este trabalho tem como objetivo avaliar um curso autoinstrucional sob a perspectiva dos cursistas, por meio de análise de narrativas. Foram avaliados discentes do curso de extensão "Odontologia para pacientes com comprometimento sistêmico" disponibilizado pela Universidade Aberta do Sistema Único de Saúde da Universidade Federal do Maranhão (UNA-SUS/UFMA) no ano de 2017. Trata-se de um estudo descritivo com abordagem qualitativa baseada nas narrativas coletadas através do SigU Questionário. A análise das narrativas foi realizada a partir da análise de conteúdo. Os núcleos de sentido relacionaram-se ao conteúdo, aspectos pedagógicos, prática profissional, modalidade EaD, arquivo offline e plataforma. Foram avaliados positivamente a atualização e qualidade teórica do livro online, além dos aspectos pedagógicos aplicados, como o dinamismo do material, recursos interativos, audiovisuais e infográficos. A utilidade dos conteúdos abordados para a prática profissional foi indicada como ponto relevante da oferta educacional aliada à autonomia e flexibilidade proporcionada pela modalidade EaD. Como aspectos avaliados negativamente identificou-se a não disponibilização dos materiais para download ou modo offline e dificuldades para gerenciamento e acesso da plataforma virtual de ensino. Estudos desta natureza contribuem para o aprimoramento da modalidade EaD potencializando a democratização e acesso ao conhecimento.
\end{abstract}

Palavras-chave: Educação à distância. Educação Permanente em Saúde. Avaliação. 


\section{INTRODUÇÃo}

O crescente uso de tecnologias da informação e comunicação (TIC) aplicadas ao ensino tem potencializado os alcances da educação a distância. De acordo com o Censo EaD referente ao ano de 2016, no Brasil foram ofertados mais de 1200 cursos livres para atualização profissional (ABED, 2017). Diante desse cenário de expansão, os investimentos para a promoção de aprendizagem efetiva nesta modalidade tornam-se uma necessidade constante, na qual processos avaliativos são fundamentais para a melhoria desse processo.

A educação a distância $(\mathrm{EaD})$ permite a ampliação e democratização do acesso aos conhecimentos. Assim, esta modalidade de ensino surge como uma possibilidade de potencializar a disseminação da Educação Permanente em Saúde (EPS) (SANTOS et al., 2018a). A partir da EaD, a educação em e para a saúde vem sendo repensada, visto que são necessárias posturas inovadoras em relação ao processo de aprendizagem, tanto para os aprendizes quanto para os formuladores dos materiais didáticos.

Para atender a demanda de qualificação dos profissionais do SUS o Sistema Universidade Aberta do SUS (UNA-SUS) foi instituído pelo Decreto ํㅜ 7.385, de 8 de dezembro de 2010 (BRASIL, 2010). O objetivo desse sistema é facilitar o acesso dos profissionais de saúde à educação, por meio de uma plataforma online, principalmente aqueles locados em áreas remotas do país. A criação do Sistema UNA-SUS pontua a importância dos investimentos em processos educativos que incorporem a educação às práticas cotidianas, a fim de qualificar todos os atores envolvidos no cuidado em saúde (GIGANTE; CAMPOS, 2016).

Estratégias educacionais a distância são uma realidade para a educação permanente na área da saúde. Assim, dentre diversos tipos de cursos na modalidade EaD, o curso autoinstrucional surge como um grande potencial visto que propicia ao aluno uma maior autonomia e independência. Esses cursos, tradicionalmente, são modelos educacionais que não utilizam de estratégias colaborativas ou mediação de tutores (RAMOS, 2005), permitindo ao discente uma maior liberdade em relação aos horários e prazos de estudo, por exemplo.

Para a melhoria do processo de ensino-aprendizagem é fundamental realização de avaliações do material educacional ofertado. Segundo Carlini e Ramos (2009), a avaliação de cursos EaD é capaz de diagnosticar o desempenho de todos os elementos constituintes, analisando a contribuição para a realização dos objetivos propostos, bem como detectando as alterações necessárias, a forma e o momento adequados para 
realizá-las. Tendo em vista que o objetivo primordial de qualquer estratégia de ensino é a formação do discente, o uso da avaliação torna-se fundamental para 0 desenvolvimento de projetos em EaD na medida em que fornece feedbacks fornecidos pelo público-alvo.

\section{OBJETIVOS}

\subsection{Geral}

- Analisar um curso autoinstrucional sob a perspectiva dos cursistas, a partir da análise de narrativas.

\section{PROCEDIMENTOS METODOLÓGICOS}

Trata-se de um estudo descritivo de abordagem qualitativa, realizado a partir da análise de narrativas de discentes do curso de extensão "Odontologia para pacientes com comprometimento sistêmico", desenvolvido na modalidade autoinstrucional e ofertado pela UNA-SUS/UFMA.

Os alunos inscritos nas duas ofertas do curso, realizadas no ano de 2016 e 2017, foram convidados a responder um questionário online hospedado na plataforma Moodle, utilizando o SigU Questionário - ferramenta que auxilia no monitoramento e avaliação dos cursos ofertados pela instituição. Não houve identificação sociodemográfica dos participantes, por se tratar de uma pesquisa de satisfação anônima.

Foram avaliadas as narrativas que respondiam o seguinte item do questionário online: "Indique aqui quais foram sua melhor e pior experiência no módulo. Aproveite e faça suas sugestões para que possamos melhorar continuamente a qualidade do curso." Assim, gerou-se um total de 187 narrativas para serem analisadas. $O$ tratamento dos dados foi realizado em 3 (três) etapas principais: a pré-análise; a exploração do material e o tratamento dos resultados; a inferência e a interpretação (FARAGO; FOFONCA, 2012).

A pré-análise corresponde a etapa inicial de organização das narrativas. Nessa fase realizou-se leitura flutuante das narrativas, organizadas em planilha no Microsoft Excel 2010. A partir da leitura, as narrativas foram divididas em três categorias: I) melhor experiência no curso; II) pior experiência no curso; III) sugestões; IV) narrativas sem possibilidade de avaliação (por serem incompreensíveis devido à falta de coerência na redação ou apresentarem frases genéricas não relacionados à satisfação do discente 
em relação ao curso).

A etapa seguinte correspondeu a realização de uma segunda leitura flutuante, em todos os itens de cada categoria, para a organização das narrativas em núcleos de sentidos. Os resultados da análise das narrativas serão apresentados de forma descritiva, a partir dos núcleos de sentidos que deram origem a construção dos temas. Em pesquisa qualitativa, a noção de tema está relacionada a uma afirmação acerca de determinado assunto, podendo ser representada por uma frase ou resumo, conforme afirma Minayo (2010).

\section{APRESENTAÇÃO E DISCUSSÃO DOS RESULTADOS}

A EaD é uma importante ferramenta para o desenvolvimento de práticas de educação e qualificação dos recursos humanos na área da saúde (SANTOS, 2018a). Nesse sentido, a avaliação é uma etapa fundamental no processo educacional, sobretudo quando é produto das vivências reais dos usuários no momento da utilização. A partir desse estudo foi possível analisar sob a ótica dos discentes os aspectos pedagógicos, teóricos e tecnológicos envolvidos no processo de ensino-aprendizagem.

No decorrer da história da educação, o material didático constituiu-se como um dos pilares do processo de ensino e aprendizagem (HEINSFELD; PENA, 2017). Por meio das narrativas analisadas, foi possível identificar a visão dos alunos com relação ao conteúdo abordado no curso, no que diz respeito à atualização do referencial utilizado, bem como os aspectos pedagógicos utilizados, ressaltando a didática aplicada, assim como os recursos interativos e audiovisuais, como podemos observar nos depoimentos abaixo:

"[...]Ótimo conteúdo, bem abordado, literatura bem atualizada e facilidade de compreensão!" "Achei o curso bem dinâmico, com dados atuais e literatura bem referenciada"

"A presença de botões clicáveis e infográficos melhorou muito a aprendizagem durante os módulos."

Nota-se que a qualidade do curso é avaliada positivamente pelo fato de possuir material didático atualizado e ser apresentado de forma dinâmica. Clementino (2015) pontua que com a ampliação e crescente crescimento da oferta de cursos e capacitações na educação a distância, o planejamento de materiais didáticos instrucionais tornou-se parte fundamental para concepção de projetos nesta forma de ensino.

$\mathrm{Na} \mathrm{EaD}$, o material didático assume o papel de fio condutor, já que organiza o desenvolvimento e a dinâmica de todo o processo de ensino e aprendizagem (HEINSFELD; PENA, 2017). Por se tratar de um curso autoinstrucional, é importante 
ressaltar que o material didático deve ser auto suficiente, isto é, a produção do conteúdo deve ser planejada de forma clara, baseando-se nos objetivos elencados pela equipe pedagógica, com o intuito de desenvolver a autonomia e independência do discente durante a sua capacitação.

Conforme o Censo EaD (ABED, 2017), os cursos de atualização constituem uma boa opção para profissionais que buscam expandir os horizontes educacionais. No ano de 2016, esta tipologia representou o primeiro lugar no ranking de cursos livres não corporativos na modalidade EaD e este dado representa um alinhamento das ofertas educacionais às demandas dos profissionais em atuação que visam melhorar suas habilidades. Nesse estudo, os discentes mostram-se satisfeitos com o esclarecimento de dúvidas vivenciadas no cotidiano profissional, ressaltando a relevância do conteúdo para tal, conforme observa-se no trecho abaixo:

\footnotetext{
"O conteúdo abordado é muito rico e vai ajudar bastante na prática diária. Temas que não foram abordados dessa maneira na faculdade."

"Foi muito importante para conhecer protocolos de atendimento desses pacientes e o fluxograma que devemos seguir para garantir a eficiência e integralidade do serviço."

"A melhor experiência foi a oportunidade de ter acesso a um conteúdo atual e extremamente importante para minha área de atuação."
}

Este dado é corroborado por Mattos, Dahmer e Magalhães (2015), no qual foi possível observar a percepção dos alunos em relação ao potencial da EaD para a educação permanente em saúde, sendo apontada como ferramenta capaz de qualificar o atendimento à população. Fato também identificado no trabalho de Santos et al. (2018a), realizado com alunos participantes de cursos de atualização em saúde bucal, no qual a maioria relatou a importância para a prática da profissão, além de enfatizarem a melhora no desempenho profissional após sua realização.

Entretanto, mesmo reconhecendo a importância do curso para a prática profissional, a atualização do conteúdo e a didática empregada, alguns discentes sugeriram um maior aprofundamento quanto à abordagem dos assuntos específicos da Odontologia e inserção de mais recursos direcionados à prática profissional, conforme relatado nas narrativas:

"[...] sugeriria que fossem dadas abordagens mais amplas sobre a abordagem de aspectos de interesse odontológico tanto no que se refere aos aspectos teóricos quanto práticos no que se refere ao manejo dos pacientes portadores das patologias sistêmicas abordadas no tema."

"Para ficar mais didático, se fosse possível, apresentar vídeos curtos, casos clínicos que poderiam acontecer na nossa prática clínica."

Pode-se pensar em dois fatores envolvidos nesses relatos. O primeiro deles pode estar 
relacionado a escassez de cursos a distância voltados à educação permanente em saúde bucal (SANTOS et al., 2018a), o que torna este um público carente de oportunidades de formação que acaba por esperar do curso além do proposto pelo objetivo inicial do mesmo. O segundo fator, relacionado à maior exploração da aplicação prática dos conteúdos, indica a necessidade de investimentos em estratégias de contextualização dos temas tratados. Conforme Filatro e Cairo (2015), um dos aspectos da dimensão pedagógica de materiais para EaD inclui o caráter transferível e aplicável dos conteúdos, os quais ressaltam as contribuições do recurso educacional para aplicação do aprendizado no cotidiano.

No contexto da $\mathrm{EaD}$, especialmente em cursos não tutorados, os materiais didáticos são centrais na mediação do processo de ensino-aprendizagem (CORRÊA, 2013). A produção de cursos nesta modalidade deve estar alinhada ao uso das TICs, para que possam colaborar para a ressignificação do aprendizado e, consequentemente, favorecer a construção da aprendizagem significativa (FILATRO;CAIRO, 2015). Um dado relevante refere-se ao fato de todos os respondentes terem avaliado negativamente a não disponibilização do material para download ou no formato offline, conforme observa-se nos relatos abaixo:

"Excelente material, porém senti falta do livro em pdf, isso dificulta para o aluno ler sem estar com internet."

"A 'pior' foi que senti um pouco de dificuldade de acompanhar o conteúdo por conta que não tinha a opção de download do mesmo (PDF)."

A necessidade de material no formato offline apontada pelos cursistas pode ser justificada por características positivas particulares dos materiais impressos, como a facilidade de utilização e transporte, além da possibilidade de anotações acerca dos estudos (CORRÊA, 2013). Apesar dos avanço de uso das TICs na educação online, o material impresso contribui para acesso aos conteúdos trabalhados em contextos não vinculados ao ambiente virtual ou até mesmo o uso para consultas após a finalização do curso, o que torna-se uma característica favorável para o exercício da autonomia do cursista na condução do processo de ensino-aprendizagem.

É possível inferir que este dado indica uma afinidade dos cursistas com o material impresso pelos motivos supracitados quanto à facilidade de acesso, quanto como reflexo das vivências do modelo tradicional de ensino presencial, onde normalmente os discentes possuem um material de apoio na forma de livro didático. Ressalta-se, portanto, um momento contemporâneo de transição entre modelos educacionais e de variedades de suportes para a informação que devem ir se adaptando a vivência e hábitos de cada indivíduo (SANTOS et al., 2018b). Institucionalmente, avalia-se que há necessidade de orientar melhor os cursistas sobre os espaços onde os materiais do 
curso estão disponíveis offline, como na loja de aplicativos SAITE STORE que requer único download.

As funções exercidas pelos materiais didáticos variam historicamente quanto ao ambiente sociocultural e à época em que estão inseridos, às disciplinas e aos níveis de ensino, aos métodos e às formas de utilização (CHOPPIN, 2004). Na EaD, pode-se dizer que os materiais didáticos, incluindo os impressos, são um grande campo de análise, visto que compõem importantes partes do processo de aprendizagem na EaD, tendo como uma das funções a facilitação da construção do conhecimento (HEINSFELD; PENA, 2017).

O acesso aos recursos disponíveis nas plataformas exigem conhecimentos prévios acerca do uso de TICs. A análise das narrativas apontou para uma certa "insatisfação" dos cursistas quanto ao manuseio do ambiente de aprendizagem na qual o curso foi disponibilizado. A maioria dos alunos relatou dificuldades para gerir aspectos organizacionais do curso, como geração de documentos, certificação e manuseio das ferramentas disponíveis, mesmo estando disponível um tutorial para orientação.

"Minha maior dificuldade inicial foi a plataforma, porque nunca anteriormente havia feito um curso EAD."

Estes relatos são congruentes com os achados de Brasil (2018) no qual os cursistas também apontaram dificuldade na utilização do ambiente virtual. A necessidade de conhecimentos tecnológicos prévios também foi ressaltada na pesquisa feita por Languardia, Casanova e Machado (2010) onde os participantes apontaram que a existência de experiência prévia acerca do uso de computadores e internet seria uma variável facilitadora para a navegação no ambiente virtual.

Pensando no contexto dos cursos autoinstrucionais, quando os alunos não possuem a figura do tutor, é fundamental buscar estratégias que facilitem a navegabilidade. Nesse sentido, Manzini afirma que

(...) quanto menos habilidoso o usuário, mais o sistema deve ser capaz de compensar sua carência de habilidades, fornecendo o que ele não sabe ou não pode fazer. Além disso, quanto menos motivado for o usuário, mais o sistema deve ser não apenas amigável, mas também atraente, ou seja, participar ativamente de uma organização colaborativa deve ser considerado estimulante (2008, p. 85).

O trabalho de Santos et al. (2018a) discute que a dispersão geográfica das equipes de saúde bucal e pela carga horária de trabalho dos cirurgiões-dentistas de maneira geral são empecilhos para o acesso à educação permanente. Assim a estratégia a distância se mostra como uma possibilidade de formação para este público. Tal fato também foi observado no nosso estudo, no qual os alunos consideraram positiva a autonomia e 
liberdade no processo de ensino-aprendizagem proporcionado pela modalidade EaD, conforme podemos observar nos trechos:

"A melhor experiência foi ter liberdade para fazer meu horário de estudo."

"Melhor é a facilidade para acessar os módulos no nosso tempo (na hora livre)."

Segundo Santos (2018a), a EaD têm contribuído de forma substancial para o desenvolvimento dos recursos humanos na área saúde, tanto no processo de formação contínua quanto na atualização das práticas, resultando em um novo espaço de aprendizagem para construção do conhecimento. A EaD democratiza o acesso à educação, incentiva a educação permanente e permite a atualização e o aperfeiçoamento profissional, exigindo menor quantidade de recursos financeiros (NUNES, 2010).

\section{CONSIDERAÇÕES FINAIS}

A avaliação é uma etapa indispensável do processo de ensino-aprendizagem, principalmente nos cursos EaD autoinstrucionais, pois é o momento em que os cursistas podem expressar feedbacks da vivência na oferta educacional. Os resultados deste estudo trazem informações importantes para a qualificação do processo de trabalho da equipe pedagógica da UNA-SUS/UFMA, na medida que possibilita reflexões acerca das práticas adotadas e indica percursos para melhoramentos futuros.

Com base nos achados, é possível perceber o potencial dos cursos de atualização nesta modalidade, especialmente pela possibilidade de acesso autônomo e flexível à conteúdos relevantes para a prática profissional dos cursistas. Além disso, nota-se a importância do planejamento de estratégias didático-pedagógicas adaptadas à esta tipologia de ensino ponto relevante do processo.

As dificuldades de acesso à plataforma e disponibilização de material didático em outros formatos, que não online mostram-se como desafios para o ensino no formato EaD e indicam necessidades de avanços na interface tecnológica adaptadas aos ambientes virtuais de aprendizagem.

\section{REFERÊNCIAS}

ABED. Censo EAD.BR: relatório analítico da aprendizagem a distância no Brasil $2016=$ Censo EAD. BR: analytic report of distance learning in Brazil 2016/[organização] ABED Associação Brasileira de Educação a Distância. Curitiba: InterSaberes, 2017. 
BRASIL. G. V. S.; Análise de um curso de especialização em atenção básica através de narrativas de estudantes do programa mais médicos. 2018. 66f. Dissertação (Mestrado em Saúde do Adulto) - Universidade Federal do Maranhão, 2018.

BRASIL. Ministério da Casa Civil. Decreto no 7.385, de 08 de dezembro de 2010. Diário Oficial [da] República Federativa do Brasil. Brasília, 09 dez. 2010; Seção 1, p. 1. [b].

CAMPOS, K. A.; SANTOS, F.M. A educação a distância no âmbito da educação permanente em saúde do Sistema Único de Saúde (SUS). Rev. Serv. Público, Brasília, v. 67, n. 4, p.603-626, out/dez 2016.

CARLINI, A. L.; RAMOS, M. P. A avaliação do curso. In: LITTO, Fredric M.; FORMIGA, Marcos. Educação a distância: o estado da arte. São Paulo: Pearson Education, 2009. pp. 161-165.

CHOPPIN, A. História dos Livros e das edições didáticas: sobre o estudo da arte. Educação e pesquisa, v. 30, n. 3, p. 549-566, 2004.

CLEMENTINO, A. Planejamento pedagógico para cursos EAD. In: KENSKI, Vani Moreira. Design Instrucional para cursos on-line. São Paulo: Editora Senac São Paulo, 2015.

CORRÊA, M.A. Os materiais didáticos como recursos fundamentais de potencialização da qualidade do ensino e aprendizagem na EaD. E-tech: Atualidades tecnológicas para competitividade industrial, Florianópolis, v. 6, n. 1, p.125-140, 2013.

FARAGO, C. C.; FOFONCA, E. A análise de conteúdo na perspectiva de Bardin: do rigor metodológico à descoberta de um caminho de significações. Revista Linguagem, v. 18, 2012.

FILATRO, Andrea; CAIRO, Sabrina. Produção de conteúdos educacionais. São Paulo: Saraiva, 2015.

GIGANTE, R.L.; CAMPOS, G.W.S. Política de Formação e Educação Permanente em Saúde no Brasil: bases legais e referências teóricas. Trab. Educ. Saúde, Rio de Janeiro, v. 14 n 3, p.747-763, set./dez, 2016. 
HEINSFELD, B.D.S. S.; PENA, A. L. Design educacional e material didático impresso para educação a distância: um breve panorama. Revista Brasileira de Estudos Pedagógicos, v. 98, n. 250, 2017.

LAGUARDIA, J.; CASANOVA, A.; MACHADO, R. A experiência de aprendizagem online em um curso de qualificação profissional em saúde. 2010. Trabalho, Educação e Saúde. Rio de Janeiro, v. 8, n.1, p. 97-122, 2010.

MANZINI, E. Design para a inovação social e sustentabilidade: comunidades criativas, organizações colaborativas e novas: redes projetuais. Rio de Janeiro:E-papers, 2008.

MINAYO, M.C.S. O Desafio do Conhecimento: Pesquisa Qualitativa em Saúde. São Paulo: Ed. Hucitec-Abrasco, 2010.

MATTOS, L. B.; DAHMES, A.; MAGALHÃES, C. R. Contribuição do curso de especialização em Atenção Primária à Saúde à prática de profissionais da saúde. ABCS Health Sci., v. 40, n.3, p. 184-189, 2015.

NUNES, C. S. Análise da criação e compartilhamento do conhecimento no curso de administração a distância da UFSC - Projeto Piloto. 2010. 69 f. Trabalho de conclusão de curso em Administração. Universidade Federal de Santa Catarina, Florianópolis, 2010.

RAMOS, D. K. Aspectos pedagógicos e tecnológicos da concepção e desenvolvimento de propostas de E-learning. Colabor@ - A Revista Digital da CVA-RICESU, 2005, v. 3, n. 9.

SANTOS, C. M. et al. Avaliação da qualidade de aprendizagem no ambiente virtual (Moodle) em saúde bucal, na perspectiva dos discentes. Rev da ABENO, v. 18, n. 1, p. 116-123, 2018a.

SANTOS, M. L. F. B. et al. Do impresso ao virtual: atitudes das paperless society no uso da informação. Revista EAD em Deb@te, n. 4, p. 28-36, 2018b 